\title{
Abdominal Wall Desmoid Tumour Diagnosis on CT Scan - A Case Report
}

\author{
Amruta Dinesh Varma ${ }^{1}$, Rajasbala Pradeep Dhande², Suhasini Pattabiraman ${ }^{3}$ \\ 1,2,3 Department of Radio-Diagnosis, Jawaharlal Nehru Medical College, \\ Datta Meghe Institute of Medical Sciences, Wardha, Maharashtra, India.
}

\section{INTRODUCTION}

Desmoid tumour also known as aggressive fibromatosis, has similarities with malignant tumour fibrosarcoma, but are benign as they don't metastasize to other parts of the body. Desmoid tumours are very rare with an incidence of 2 - 4 per million per year and constitute $0.03 \%$ of all tumours with slight female predominance seen around $3^{\text {rd }}$ to $4^{\text {th }}$ decade $^{1}$ and if it occurs in young age, have aggressive course with high chances of recurrence. ${ }^{2}$ These are rare mesenchymal neoplasms having a consistency like a fibrotic band. ${ }^{3}$ On gross appearance they have speculated infiltrative margins and are adherent to adjacent structures. Microscopically, they are made of fibroblasts in dense collagen stroma and poorly defined fascicles of uniform spindle cells. They show less mitotic activity and less chances of necrosis. ${ }^{1,4}$ Here we are presenting a rare case of 45 -year-old woman who presented with pain and lump in abdomen, who was advised contrast computed tomography (CT).

\section{PRESENTATION OF CASE}

A 45-year-old woman presented with pain and gradually progressive lump in abdomen since 6 months in right iliac fossa with no history of trauma. On local examination the mass was immobile, firm in consistency with no local tenderness. She had a surgical scar mark, from her two caesarean sections. No other significant surgical history was present. In view of above findings she was advised CT scan. On CT there was e / o well circumscribed heterogeneously enhancing mass lesion with poorly enhancing central area in anterior abdominal wall towards right inguinal region appearing to be arising from right rectus abdominis muscle measuring approximately $6.6 \times 6.5 \times 4.7 \mathrm{cms}$ in size.
Corresponding Author: Dr. Amruta Dinesh Varma, Meghe Heights 2, Flat No. 4, DIMS Campus, Sawangi, Maharashtra, India. E-mail: amrutavarma24@gmail.com

DOI: $10.14260 /$ jemds/2021/32

How to Cite This Article:

Varma AM, Dhande RP, Pattabiraman S. Abdominal wall desmoid tumour diagnosis on CT scan- a case report. J Evolution Med Dent Sci 2021;10(03):153-155, DOI: 10.14260/jemds/2021/32

Submission 11-09-2020,

Peer Review 16-11-2020,

Acceptance 23-11-2020,

Published 18-01-2021.

Copyright ( 12021 Amruta Dinesh Varma et al. This is an open access article distributed under Creative Commons Attribution License [Attribution 4.0 International (CC BY 4.0)] 

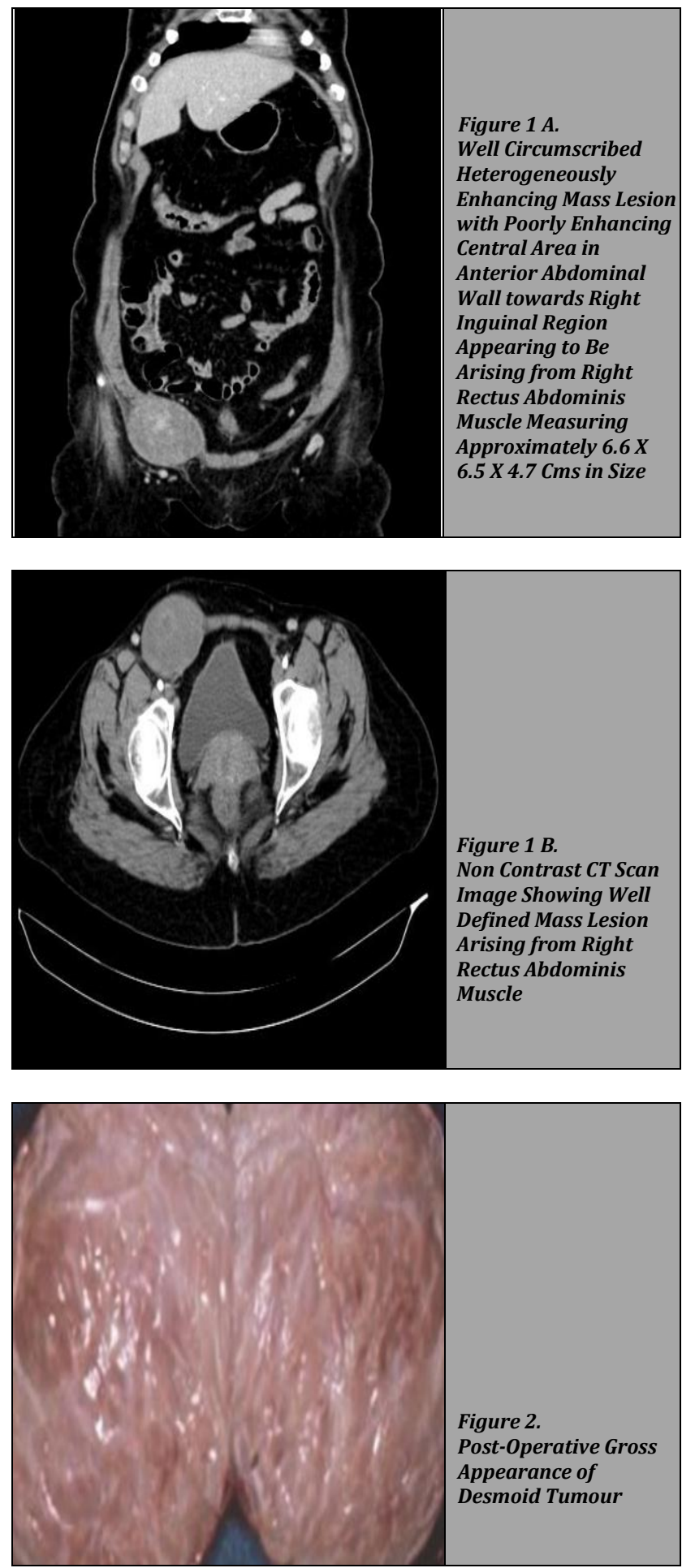

\section{DIFFERENTIAL DIAGNOSIS}

Malignant conditions like fibrosarcoma, rhabdomyosarcoma, synoviosarcoma, liposarcoma, fibrous histiocytoma, lymphoma and metastases of these conditions give intense enhancement. Benign conditions like neurofibroma, neuroma and leiomyomas don't show enhancement. Hematomas can be present at the following locations; rectus sheath, chest wall, mesentery, retroperitoneum and space of Retzius and they should be correlated with clinical history and will not show enhancement. ${ }^{7}$

\section{DISCUSSION}

Desmoid tumours are characterized by fibroblastic proliferation, without evidence of inflammation or definite neoplasia. Abdominal desmoids are more frequent in female patients. Desmoids have been associated with some structural defect in the development of connective tissue, prior lesion site, trauma at the site and multiple pregnancies listed as causative factors. An increased incidence of desmoids tumours has been found in patients with Gardner's syndrome, in patients with familial adenomatous polyposis (FAP) and other risk factors are trauma, prior surgery, pregnancy and oral contraceptive with oestrogen acting as its growth factor. Recurrence is common and adjuvant radiation therapy has been recommended with local excision. 5

Desmoid tumours of the abdominal wall arise from abdominal wall and aponeurotic structures mainly the rectus and internal oblique muscles, and their fascial coverings. Desmoids can often cross the midline to include both muscles of the rectus. They will seldom originate from the external oblique muscle and the muscle or fascia of the transversalis, and there may be its extension to the inner surface of the iliac crest and into the cavity of the abdomen. These tumours are usually seen in young, gravid women or more generally during the first year after birth. They can also originate in places where previous abdominal surgery has taken place. Most desmoids of the abdominal wall measure up to $515 \mathrm{~cm} .6$ When they emerge in the muscle of the rectus, they typically remain at their origin site. Recurrence is $20 \% 30 \% 6$ and typically becomes visible within 6 months after excision or in connection with subsequent gestations or deliveries. ${ }^{7}$ Yeola et al. have researched diagnostic laparoscopy as an important method for evaluating intra-abdominal malignancies. ${ }^{8}$

Desmoid tumours on ultrasonography appear as hypoechoic soft tissue masses with variable vascularity on Doppler. ${ }^{4}$ Soft tissue mass of heterogenous attenuation depending on necrosis and degeneration is seen on CT with variable enhancement. Owing to the penetration of neighbouring structures, margins can be indistinct. Magnetic resonance imaging (MRI) is best for the evaluation of extraabdominal desmoids because it helps desmoids with adjacent structures to be adequately evaluated. As desmoids have variable distribution of spindle cells, heterogeneous signal and inhomogeneous enhancement can have collagen and myxoid matrix. Intermediate signal strength is present on T2weighted and proton density, between skeletal muscles and subcutaneous fat collagen bundles appear as hypointense bands. ${ }^{9}$ Due to increased collagen deposition and decreasing cellularity over the period of time, they become more hypointense, but chronic or actively increasing desmoids display a higher T2 signal as they have greater cellularity. ${ }^{10}$

Daga et al. conducted ultrasound evaluation of uterine leiomyoma in perimenopausal females. ${ }^{11}$ Sharma et al. conducted a study on Gallium-68 DOTA-NOC positron emission tomography (PET) / CT as an alternate predictor of disease activity in sarcoidosis. ${ }^{12} \mathrm{~A}$ variety of radio diagnostic procedures were used in swellings of abdominal region and adjacent structures including CT and MRI by Swarnkar et al.,13,14 Talwar et al.,15 Samad et al.,16 Lamture et al.17,18 and Jindal et al. ${ }^{19}$ 
Financial or other competing interests: None.

Disclosure forms provided by the authors are available with the full text of this article at jemds.com.

\section{REFERENCES}

[1] Shields CJ, Winter DC, Kirwan WO, et al. Desmoid tumours. Eur J Surg Oncol 2001;27(8):701-6.

[2] Romero JA, Kim EE, Kim CG, et al. Different biologic features of desmoid tumors in adult and juvenile patients: MR demonstration. J Comput Assist Tomogr 1995;19(5):782-7.

[3] Dinauer PA, Brixey CJ, Moncur JT, et al. Pathologic and MR imaging features of benign fibrous soft-tissue tumors in adults. Radiographics 2007;27(1):173-87.

[4] Murphey MD, Ruble CM, Tyszko SM, et al. From the archives of the AFIP: musculoskeletal fibromatosesradiologic-pathologic correlation. Radiographics 2009;29(7):2143-73.

[5] Shinagare AB, Ramaiya NH, Jagannathan JP, et al. A to $\mathrm{Z}$ of desmoid tumors. AJR Am J Roentgenol 2011;197(6):W1008-14.

[6] Wetzel LH, Levine E. Soft-tissue tumors of the foot: value of MR imaging for specific diagnosis. AJR Am J Roentgenol 1990;155(5):1025-30.

[7] Casillas J, Sais G, Greve JL, et al. Imaging of intra- and extra abdominal desmoid tumors. Radiographics 1991;11(6):959-68.

[8] Yeola ME, Gode D, Bora AK. Diagnostic laparoscopy as an effective tool in evaluation of intra- abdominal malignancies. World Journal of Laparoscopic Surgery 2018;11(2):68-75.

[9] Kransdorf MJ, Jelinek JS, Moser RP, et al. Magnetic resonance appearance of fibromatosis. A report of 14 cases and review of the literature. Skeletal Radiol 1990;19(7):495-9.

[10] Vandevenne JE, De Schepper AM, Beuckeleer LD, et al. New concepts in understanding evolution of desmoid tumors: MR imaging of 30 lesions. Eur Radiol 1997;7(7):1013-9.

[11] Daga SR, Phatak SV. Ultrasound evaluation of uterine leiomyoma in perimenopausal females with histopathological correlation. J Evolution Med Dent Sci 2020;9(8):562-5.

[12] Sharma S, Singh AD, Sharma SK, et al. Gallium-68 DOTANOC PET/CT as an alternate predictor of disease activity in sarcoidosis. Nucl Med Commun 2018;39(8):768-78.

[13] Swarnkar M, Agrawal A. Kimura's disease. Formosan Journal of Surgery 2018;51(1):26-8.

[14] Swarnkar M, Jindal R. Obstructed obturator hernia: a diagnostic dilemma. Journal of Krishna Institute of Medical Sciences 2019;8(3):115-7.

[15] Talwar D, Kumar S, Andhale A, et al. Chilaiditi syndrome, unusual complication of rather innocuous abnormality: case report. Medical Science 2019;23(100):1011-4.

[16] Samida SA, Phatak SV. An unusual case of abdominoscrotal swelling in a young patient-hydrocele en bissac. Journal of Clinical and Diagnostic Research 2018;12(11):3-5.

[17] Lamture YR, Salunke B. Anatomical variations related to position of appendix. J Evolution Med Dent Sci 2018;7(46):5030-33.

[18] Lamture YR, Gajbhiye V. Migration of thecoperitoneal shunt into a hernial sac. Journal of Clinical and Diagnostic Research 2019;13(11):PD01-2.

[19] Jindal R, Swarnkar M. Outcomes are local: a cross sectional patient specific study of risk factors for surgical site infections in major abdominal surgeries. Journal of Krishna Institute of Medical Sciences 2020;9(1):43-50. 